\title{
Impact of uncontrolled hypertension on 12-month clinical outcomes following below-the-knee arteries (BTK) interventions in patients with critical limb ischemia
}

Sung $\| \mathrm{Im}^{1}$, Seung-Woon Rha ${ }^{2^{*}}$, Byoung Geol Choi², Se Yeon Choi ${ }^{2}$, Jae Joong Lee², Sun ki Lee², Ji Bak Kim², Jin Oh Na², Cheol Ung Choi ${ }^{2}$, Hong Euy Lim², Jin Won Kim², Eung Ju Kim², Chang Gyu Park², Hong Seog Seo ${ }^{2}$ and Dong Joo $\mathrm{Oh}^{2}$

\begin{abstract}
Background: Despite intensive anti-hypertensive treatment, overall control rates of only $30 \sim 50 \%$ have been reported in patients with hypertension (HTN). However, clinical significance and angiographic characteristics of patients with uncontrolled HTN following Below-the-knee arteries (BTK) interventions in patients with critical limb ischemia (CLI) are not clarified yet as compared to those with controlled HTN.

Methods: A total 165 consecutive hypertensive patients with BTK lesions from August 2004 to November 2012 were enrolled for this study. Uncontrolled HTN was defined as a blood pressure of $>140 \mathrm{mmHg}$ systolic and $90 \mathrm{mmHg}$ diastolic under anti-hypertensive treatment. A total of 112 patients $(67.8 \%)$ had uncontrolled HTN. We compared the clinical and angiographic characteristics of patients with uncontrolled HTN following BTK interventions to those with controlled HTN at 12-month follow-up.
\end{abstract}

Results: The baseline characteristics are well balanced between the two groups. At 12 months, there was no difference in the incidence of mortality, target lesion revascularization (TLR), target extremity revascularization (TER), and limb salvage rate in both groups. However, amputation rates were higher in patients with controlled HTN (33.9 vs. $19.6 \%, P=0.045$ ).

Conclusion: Regardless of blood pressure control, HTN itself was an independent risk factor for BTK lesions, suggesting more intensive medical therapy with close clinical follow up will be required for all BTK patients with HTN.

Keywords: Uncontrolled hypertension, Below-the-knee artery (BTK) lesion, Peripheral angioplasty

\section{Background}

Hypertension (HTN) is probably the most common risk factor of atherosclerotic cardiovascular disease. Atherosclerotic cardiovascular disease is the leading cause of mortality in Western countries [1]. Peripheral arterial disease (PAD), which is usually defined as atherosclerotic occlusion of the arterial bed in the lower extremities, is a major manifestation of systemic atherosclerosis. It is well known that PAD is associated with increased risk of

\footnotetext{
* Correspondence: swrha617@yahoo.co.kr

${ }^{2}$ Cardiovascular Center, Korea University Guro Hospital, 80, Guro-dong,

Guro-gu, Seoul 152-703, South Korea

Full list of author information is available at the end of the article
}

mortality from cardiovascular disease (CVD) and all causes such as cerebrovascular diseases, renal disease, and diabetes mellitus (DM). In addition, it is an independent risk factor for mortality and morbidity in patients with CVD [2-4]. Therefore, the clinical importance of PAD has increasingly been acknowledged in recent several years [5].

Critical limb ischemia (CLI), characterized by ischemic rest pain or tissue loss, represent the most advanced state of PAD, burdened by high morbidity and mortality. CLI generally occurs in high risk patients with several risk factors including DM, older age, HTN with extensive atherosclerotic disease of below-the-knee vessels. 
Previous study also showed that PAD is significantly associated with systolic hypertension in the high risk group [6].

HTN currently affects $25 \%$ of adults and may affect $>90 \%$ of individuals during their lifetimes [7]. Therefore adequate control of blood pressure is of public health importance. However, recent studies indicated that $30 \sim 50 \%$ of those with HTN are either untreated or under-treated [8]. No previous study of PAD has been performed in patients with uncontrolled HTN. Clinical significance and angiographic characteristics of patients with uncontrolled HTN following Below-the-knee arteries (BTK) interventions in patients with CLI are not clarified yet as compared to those with controlled HTN.

In this study, we sought to clarify the impact of uncontrolled HTN on clinical outcomes in patients with CLI following BTK interventions during 12 months follow-up.

\section{Methods}

\section{Study population}

We performed peripheral angiography (PAG) in 180 consecutive patients (male $76.7 \%$, mean age $67.1 \pm$ 10.9 years) who had typical or atypical claudication or wound to confirm significant PAD at cardiovascular center in Korea University Guro Hospital, Seoul, South Korea.

From August 2004 to November 2012, all consecutive hypertensive patients with CLI undergoing angioplasty of at least 1 BTK vessel at our center were screened for enrollment. Inclusion criteria were the presence of hypertension, CLI (Rutherford class 4 or greater), stenosis or occlusion $\geq 40 \mathrm{~mm}$ of at least 1 tibial vessel with distal run-off to the foot, and agreement to 12-month angiographic evaluation.

The patients were excluded if they had one of the following conditions including advanced heart failure (New York Heart Association class III or IV), serum creatinine $\geq 3 \mathrm{mg} / \mathrm{dL}$, life expectancy $<1$ year, contraindication to combined antiplatelet treatment, planned major amputation before angiography because these conditions can be major causes of adverse cardiovascular events and could serve as the bias of PAD and the patients without HTN.

Finally, a total 165 hypertensive patients $(91.6 \%$ of total subjects underwent PAG) with angiographic proven PAD were enrolled for this study and underwent peripheral angioplasty. Those patients were divided into two groups according to blood pressure (BP) control (controlled HTN group; $n=53$ patients, uncontrolled HTN group; $n=112$ patients) and analyzed. The study flow chart was shown in Fig. 1. We compared the clinical and angiographic characteristics, and major clinical outcomes after BTK

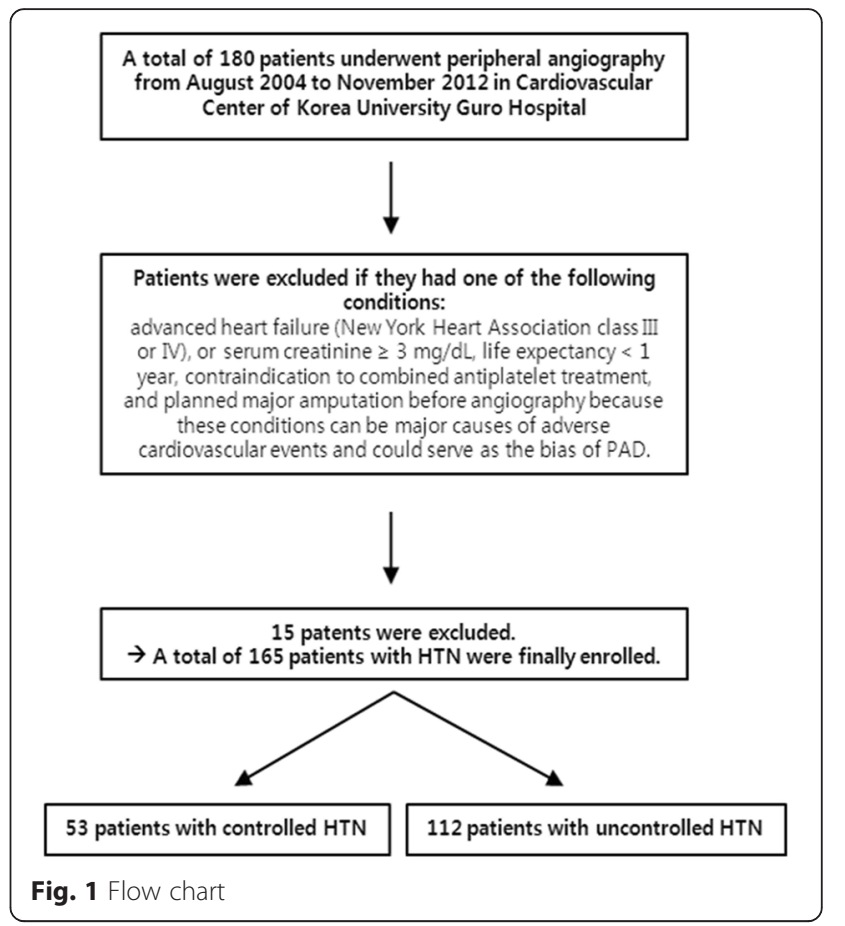

interventions up to 12 months in patients with HTN according to presence of BP control.

\section{Study definition}

Hypertension was defined as either systolic or diastolic elevation of blood pressure $\geq 140 / 90 \mathrm{mmHg}$ or ongoing antihypertensive pharmacological treatment. The physician measured blood pressure with sphygmomanometer with patients in a sitting posture, after resting for at least $5 \mathrm{~min}$ with the cuff placed on the arm. In each patient, the mean of two readings taken at intervals of at least 2 min was used in the study. The blood pressures were measured for all patients every three months from the enrollment. Uncontrolled HTN was defined as a blood pressure of $>$ $140 \mathrm{mmHg}$ systolic and $90 \mathrm{mmHg}$ diastolic under anti-hypertensive treatment including patients who lack blood pressure control secondary to poor adherence and/or an inadequate treatment regimen, as well as those with true treatment resistance. Dyslipidemia was defined as a total cholesterol level $\geq 200 \mathrm{mg} / \mathrm{dL}$ or current treatment with lipid-lowering drugs. Current smoking was defined as active smoking within the past 12 months. Diabetes mellitus (DM) was defined as the fasting blood glucose level $\geq$ $126 \mathrm{mg} / \mathrm{dL}$, or use of oral hypoglycemic agents or insulin. In the present study, if a patient's past history, medical records, present symptoms or medical examination results accorded with one of the following criteria, the patients were diagnosed with PAD: (1) Claudication with ankle brachial indices $<0.90$; (2) 
Claudication with findings of a significant lesion $(\geq 70 \%$ diameter stenosis) in peripheral artery on computed tomographic angiography (CTA) or invasive angiography; (3) Symptomatic carotid, subclavian arterial disease ( $\geq 70 \%$ diameter stenosis) documented by image studies including CTA or invasive angiography. Insignificant CAD was defined as the $\leq 30 \%$ diameter stenosis in peripheral arteries documented by image studies including CTA or invasive angiography.

\section{Study procedure}

After admission, the femoral, popliteal, dorsalis pedis and posterior tibial arteries were palpated, and the extent of tissue loss was recorded as part of the preprocedural study. Angioplasties were performed with crossover approach or an anterograde ipsilateral approach using $5 \sim 6$ French sheaths. In case of failure to recanalize by either intraluminal or subintimal approach, a retrograde approach was attempted. After placing the sheath, intra-arterial heparin $(70 \mathrm{IU} / \mathrm{kg}$ heparin) was routinely administered via the vascular sheath. A 0.014-in. guide wire was advanced into the lesion and a balloon catheter of optimal size was introduced. The appropriate balloon length and diameter were determined by visual assessment. Balloon inflation with normal pressure was maintained for at least $120 \mathrm{~s}$. All patients were taking aspirin $100 \mathrm{mg}$ daily at least 1 week prior to peripheral angioplasty. Post-intervention dual antiplatelet therapy with aspirin $100 \mathrm{mg}$ and clopidogrel $75 \mathrm{mg}$ once daily or additional cilostazol $100 \mathrm{mg}$ twice a day were given at least for 4 weeks, and $100 \mathrm{mg}$ aspirin was given daily thereafter.

Technical success was defined as restoration of direct flow in the target vessel with run-off to the foot and a residual stenosis $<30 \%$. Clinical success was defined as technical success without clinical events during hospitalization. In patients with bilateral CLI, an additional procedure for the revascularization of the contralateral limb was planned in a different session to limit the risk of $\mathrm{x}$-ray exposure and contrast induced nephropathy, maintaining the same randomization arm.

\section{Follow-up}

Once discharged, patients were followed up in Korea University Guro Hospital. Office visits were scheduled every two weeks for first 2 months, once a month for the third month, and then every 3 months. Minor amputations planned before the interventions were performed 2 to 4 weeks after revascularization an included toe amputations resulting from necrosis or infection of tissues and bones with preservation of healthy surrounding tissue. All patients were scheduled to be readmitted for control peripheral angiography at 12 months. In case of clinical CLI recurrence, angiography and repeat revascularization were performed within 1 week from diagnosis. In patients undergoing clinically driven repeat angiography of the target limb between 9 and 12 months who did not show evidence of restenosis of the target lesion, scheduled angiography at 12 months was not performed.

\section{Study End points and definitions}

Before the intervention, immediately after the intervention, and at follow-up, angiography of the target vessel was performed in identical projections. The target lesion was identified by an image of the vascular anatomy and specific landmarks (collaterals, bone landmarks), with a second image showing the inflated balloons. These images were compared with follow-up angiograms.

The primary end point of the study was the comparison of the 12-month binary restenosis rates according to BP control. Restenosis was defined by angiography as a reduction in the luminal diameter $>$ $50 \%$ according to the worst angiographic view within the treated lesion plus the $10-\mathrm{mm}$ segments proximal and distal to it.

The pre-specified secondary end points of the study were (1) clinically driven target lesion revascularization (TLR) defined as repeat percutaneous intervention or surgical bypass graft resulting from angiographic evidence of restenosis at the level of the treated lesion $\pm 10 \mathrm{~mm}$ in the presence of at least 1 of the following criteria: recurrence of pain in the foot at rest that increased in the supine position, recurrence of foot lesion or evidence during follow-up of foot lesion size decrease-increase behavior or appearance of a new foot lesion; (2) major amputation, defined as unplanned amputation of the target limb in which a prosthesis was required for standing or walking, however, if the patients who refused the amputation, those patients were excluded from the analysis to reduce bias; and (3) target vessel occlusion (by CTA or invasive angiography). Acquired angiograms were reviewed by 2 blinded investigators who did not actively participate in recruitment and had no knowledge of clinical status and randomization group.

Multivariate analyses was performed for the cumulative 12-month prevalence of major adverse limb events (MALE) including total death, major amputations, TLR, and repeat BTK interventions in both groups. 


\section{Statistical analysis}

Data were analyzed according to the established standards descriptive statistics. Results were presented as numbers (percentages) of patients or medians (interquartile range) where applicable. Differences between groups stratified by blood control status in patients with HTN under anti-hypertensive medications were tested by $\mathrm{x}^{2}$ test and the Fisher's exact test for dichotomous variables and the Mann-Whitney $U$ test for continuous variables. Then, differences in clinical outcome between controlled HTN and Uncontrolled HTN groups were assessed at 12-months follow-up. Results were adjusted for age, gender and DM by logistic regression analysis. The difference in MALE between two groups during follow-up period was assessed by the Kaplan-Meier method by means of the log-rank test. All tests were 2tailed and a $p$ value of $<0.05$ was considered statistically significant. All statistical analysis was performed by means of SPSS 18.0 (SPSS Inc., Chicago, Illinois).

\section{Results}

The baseline clinical characteristics and laboratory findings of patients are shown in Table 1 . The most of variables including age, body mass index, dyslipidemia, smoking history, chronic kidney disease, congestive heart failure, and coronary artery disease were balanced between the two groups. There was no difference in baseline laboratory findings between the two groups.

Coronary angiographic and clinical parameters were shown in Table 2. There was no difference in coronary angiographic characteristics between the two groups.

The frequencies of beta blockers (BB), angiotensin converting enzyme inhibitor (ACEi), angiotensin receptor blocker (ARB), statins and antiplatelet drugs were similar between the two groups on admission and 30 days after BTK interventions in Table 3.

The procedural and peripheral angiographic characteristics at baseline are shown in the Table 4. The most frequently treated vessel was the anterior tibial artery. The incidences of severe calcification, chronic total occlusion (CTO) and proximal lesions were higher in the uncontrolled HTN group. However, Rutherford classifications, $\mathrm{ABI}$, lesion types, lesions length and procedural approach were similar between the two groups. Technical and clinical successes were obtained in $94 \%$ of all patients.

Table 5 shows the procedural complications after BTK interventions. There was no difference in procedural complications including arterio-venous (AV) fistula, pseudo-aneurysm, access site hematoma, gastro-intestinal (GI) bleeding, blood transfusion rates, contrast induced nephropathy and arrhythmia between the two groups.
Clinical and peripheral angiographic data at 12 months are presented in Table 6 . There was no difference in the incidence of mortality, myocardial infarction, cerebrovascular infarction in both groups. The incidences of TLR, target extremity revascularization (TER), limb salvage rate, binary restenosis, primary and secondary patency were also similar between the two groups at 12 months. And there was no patient who refused the amputation, if the patients were indicated. However, all patients with HTN $(n=165)$ had higher incidence of MALE compared to those without $\operatorname{HTN}(n=15)$ at 12 month follow-up (37.6 \% vs. $6.7 \%, P=0.021)$.

In univariate analysis, HTN, DM foot, regional wall motion abnormality of LV, mitral valve calcification, congestive heart failure, chronic kidney disease and dialysis were significantly associated with MALE in patients with CLI after peripheral angioplasty at 12 months. In multivariate analysis, HTN $(P=0.002)$, mitral valve calcification $(P=$ $0.040)$ and dialysis $(P=0.029)$ were independent risk factors for MALE (Table 7) at 12 months.

Kaplan-Meier curves showed that event free survivals of MALE are similar in both groups at 12 month followup $(P=0.456$; Fig. 2$)$.

\section{Discussion}

The main findings of the present study are that despite the patients with uncontrolled HTN had more proximal target lesions, higher incidences of CTO and severe calcifications, however, at 12 month follow-up, there was no difference in the incidence of mortality, TLR, TER, limb salvage rate in both groups following successful BTK endovascular revascularization. Rather, the amputation rate was higher in patients with controlled HTN compared to that of uncontrolled HTN. Therefore, it is difficult to interpret the difference in the results of the impact of BP control on mid-term clinical outcomes in hypertensive patients with CLI following BTK interventions. However, HTN itself was an independent risk factor for MALE in hypertensive CLI patients with BTK lesions, suggesting more intensive medical therapy with close clinical follow up will be required for all patients with HTN in real world clinical practice.

Previous study reported that the prevalence of PAD in patients with HTN is higher than those without HTN.[4] Essential HTN is associated with impaired regulation of vascular tone and endothelial dysfunction in the peripheral artery [9]. Evidence from these studies suggests that acetylcholine mediated as well as flowmediated dilation is impaired in essential HTN and that the dysfunction in part is related to defects in the nitric oxide system [10,11].

Guidelines published for the detection and treatment of HTN (The joint National Committee on Prevention, Detection, Evaluation and Treatment of high Blood 
Table 1 Baseline characteristics according to blood pressure control

\begin{tabular}{|c|c|c|c|c|}
\hline Variable. n\% & $\begin{array}{l}\text { Total }(n=165 \text { Pts })(n=201 \text { Limb) } \\
(n=246 \text { Lesion })\end{array}$ & $\begin{array}{l}\text { Controlled HTN ( } n=53 \text { Pts }) \\
(n=66 \text { Limb) }(n=90 \text { Lesion })\end{array}$ & $\begin{array}{l}\text { Uncontrolled HTN ( } n=112 \text { Pts) } \\
(n=135 \text { Limb) }(n=156 \text { Lesion) }\end{array}$ & $P$ Value \\
\hline \multicolumn{5}{|l|}{ Baseline characteristics } \\
\hline Gender (Male) & $128(77.5)$ & $43(81.1)$ & $85(75.8)$ & 0.550 \\
\hline Age (years) & $68.2 \pm 9.3$ & $68.8 \pm 10.2$ & $67.9 \pm 8.8$ & 0.549 \\
\hline Body mass index $\left(\mathrm{kg} / \mathrm{m}^{2}\right)$ & $23.2 \pm 3.2$ & $22.9 \pm 3.4$ & $23.3 \pm 3.1$ & 0.471 \\
\hline \multicolumn{5}{|l|}{ Diagnosis } \\
\hline Wound & $135(81.8)$ & $44(83)$ & $91(81.2)$ & 0.783 \\
\hline Diabetic foot ulcer & $124(75.1)$ & $41(77.3)$ & $83(74.1)$ & 0.652 \\
\hline Gangrene & $11(6.6)$ & $3(5.6)$ & $8(7.1)$ & 1.000 \\
\hline Claudication & $12(7.2)$ & $5(9.4)$ & $7(6.2)$ & 0.525 \\
\hline Resting pain & $16(9.6)$ & $3(5.6)$ & $13(11.6)$ & 0.228 \\
\hline \multicolumn{5}{|l|}{ Blood pressure; BP (mmHg) } \\
\hline Systolic BP & $151.7 \pm 17.3$ & $122.6 \pm 13.2$ & $165.4 \pm 19.2$ & $<0.001$ \\
\hline Diastolic BP & $76.2 \pm 45.5$ & $64.9 \pm 12.4$ & $81.5 \pm 61.2$ & 0.053 \\
\hline Heart rate & $78.9 \pm 14.7$ & $79.1 \pm 19.5$ & $78.8 \pm 12.4$ & 0.911 \\
\hline Pulse pressure $(\mathrm{mmHg})$ & $78.6 \pm 24.2$ & $57.7 \pm 0.8$ & $83.8 \pm 42.0$ & $<0.001$ \\
\hline \multicolumn{5}{|c|}{ Past medical and social history } \\
\hline Known HTN & $116(70.6)$ & $35(66.2)$ & $81(73.2)$ & 0.399 \\
\hline Diabetes & $152(92.1)$ & $49(92.4)$ & $103(91.9)$ & 1.000 \\
\hline Dyslipidemia & $8(4.8)$ & $3(5.6)$ & $5(4.4)$ & 0.713 \\
\hline Cerebrovascular disease & $32(19.3)$ & $9(16.9)$ & $23(20.5)$ & 0.676 \\
\hline Chronic kidney disease & $55(33.3)$ & $20(37.7)$ & $35(31.2)$ & 0.480 \\
\hline Dialysis & $41(24.8)$ & $15(28.3)$ & $26(23.2)$ & 0.563 \\
\hline Atrial fibrillation & $15(9.0)$ & $5(9.4)$ & $10(8.9)$ & 1.000 \\
\hline Coronary artery disease & $102(61.8)$ & $29(54.7)$ & $73(65.1)$ & 0.231 \\
\hline Myocardial infarction & $10(6.0)$ & $3(5.6)$ & $7(6.2)$ & 1.000 \\
\hline PTCA & $24(14.5)$ & $6(11.3)$ & $18(16.0)$ & 0.486 \\
\hline CABG & $10(6.0)$ & $1(1.8)$ & $9(8.0)$ & 0.170 \\
\hline Smoking & $66(40.0)$ & $21(39.6)$ & $45(40.1)$ & 1.000 \\
\hline Current smokers & $35(21.2)$ & $13(24.5)$ & $22(19.6)$ & 0.542 \\
\hline Alcoholic & 49 (29.6) & $17(32.0)$ & $32(28.5)$ & 0.716 \\
\hline Current alcoholics & $29(17.5)$ & $11(20.7)$ & $18(16.0)$ & 0.513 \\
\hline \multicolumn{5}{|l|}{ Laboratory findings } \\
\hline Fasting glucose (mg/dL) & $144.2 \pm 67.2$ & $150.2 \pm 71.9$ & $141.2 \pm 65.0$ & 0.520 \\
\hline Hemoglobin A1c (\%) & $7.4 \pm 1.4$ & $7.3 \pm 1.3$ & $7.5 \pm 1.4$ & 0.318 \\
\hline Total cholesterol (mg/dL) & $147.6 \pm 44.7$ & $146.6 \pm 48.5$ & $148.1 \pm 42.9$ & 0.842 \\
\hline Triglycerides (mg/dL) & $129.6 \pm 100.5$ & $132.0 \pm 53.0$ & $128.4 \pm 124.1$ & 0.840 \\
\hline HDL cholesterol (mg/dL) & $36.3 \pm 11.5$ & $35.9 \pm 12.3$ & $36.6 \pm 11.2$ & 0.725 \\
\hline LDL cholesterol (mg/dL) & $90.0 \pm 37.3$ & $89.0 \pm 38.2$ & $90.5 \pm 36.9$ & 0.819 \\
\hline hsCRP (mg/L) & $20.3 \pm 38.6$ & $25.3 \pm 37.5$ & $18.0 \pm 39.1$ & 0.439 \\
\hline Albumin (g/dL) & $3.8 \pm 1.6$ & $4.1 \pm 4.0$ & $3.6 \pm 0.5$ & 0.400 \\
\hline
\end{tabular}


Table 1 Baseline characteristics according to blood pressure control (Continued)

\begin{tabular}{lllll}
\hline Uric acid $(\mathrm{mg} / \mathrm{dL})$ & $5.5 \pm 1.8$ & $5.6 \pm 1.6$ & $5.4 \pm 1.8$ & 0.559 \\
Creatinine $(\mathrm{mg} / \mathrm{dL})$ & $2.6 \pm 3.1$ & $2.8 \pm 3.1$ & $2.5 \pm 3.0$ & 0.595 \\
Magnesium $(\mathrm{mEq} / \mathrm{L})$ & $1.7 \pm 0.2$ & $1.7 \pm 0.2$ & $1.7 \pm 0.3$ & 0.615 \\
\hline
\end{tabular}

Values are mean \pm SD (range). HTN indicates hypertension group, Pts patients, AF atrial fibrillation, PTCA percutaneous transluminal coronary angioplasty, HDL high dense lipoprotein, $L D L$ low dense lipoprotein, $h s-C R P$ high sensitive $C$-reactive protein

Pressure, and European Society of Cardiology) recommend PAD as evidence of clinical cardiovascular disease. Hypertensive patients with PAD need drug therapy no matter which stages of hypertension they are in [12]. However, due to the lack of specific PAD symptoms, clinical awareness of PAD is very low in the primary care setting, which translates into missed opportunities to treatment of HTN in hypertensive patients with PAD. Even though the hypertensive patients knew that they had high blood pressure, $30 \sim 50 \%$ of those with HTN are either untreated or undertreated [8].

Previous meta-analyses of randomized placebocontrolled trials indicate that antihypertensive therapy in patients with uncontrolled HTN reduces the risk of major cardiovascular adverse events (stroke by $30 \%$, coronary heart disease by $10 \%$ to $20 \%$, congestive heart failure by $40 \%$, and total mortality by $10 \%$ ) [13], which can be conversely interpreted that uncontrolled HTN can be very important risk factor for cardiovascular adverse events. Although, it remains controversial whether the risk of cardiovascular events is related solely to the blood pressure achieved or also to the manner in which it is achieved [7]. And recent study also reported that the risk of PAD was increased with increasing HTN grade (HTN grade 3 , OR 1.62, $P=0.006$ ) [14], and recent national review reported that the hypertensive patients with major lower extremity amputations had higher incidence of below the knee amputations than above the knee amputations, which is suggesting that HTN can affect smaller and more distal vessels of lower extremities [15].

Therefore, we hypothesized that uncontrolled HTN also can affect the mid or long term clinical outcomes after BTK interventions in hypertensive patients with CLI. This is the first study to compare the 12 months clinical outcomes after BTK interventions in hypertensive patients with according BP control.

CLI represents the most severe stage of peripheral vascular disease, with complications of limb loss [16, 17]. The clinical presentations range from rest pain, ischemic ulcers to gangrene. Apart from the potential loss of limb which is usually evident at presentation, the co-existent cardiovascular morbidity and mortality presents an even greater threat. Previous longitudinal follow-up studies have been shown that HTN is amongst the most important risk factors for PAD along with increasing age, smoking, DM and dyslipidemia [18-20].

In this study, the peripheral angiographic characteristics at baseline showed that the incidences of severe calcification, CTO and proximal lesions were higher in the

Table 2 Coronary angiographic and clinical parameters according to blood pressure control

\begin{tabular}{|c|c|c|c|c|}
\hline Coronary artery disease & $\begin{array}{l}\text { Total ( } n=165 \text { Pts })(n=201 \text { Limb) } \\
(n=246 \text { Lesion) }\end{array}$ & $\begin{array}{l}\text { Controlled HTN ( } n=53 \text { Pts) } \\
(n=66 \text { Limb) ( } n=90 \text { Lesion) }\end{array}$ & $\begin{array}{l}\text { Uncontrolled HTN ( } n=112 \text { Pts) } \\
(n=135 \text { Limb) ( } n=156 \text { Lesion) }\end{array}$ & $P$ Value \\
\hline Stents implantation & $57(34.5)$ & $20(37.7)$ & $37(33.0)$ & 0.601 \\
\hline Routine CAG & $138(83.6)$ & $31(77.5)$ & 107 (85.6) & 0.226 \\
\hline \multicolumn{5}{|l|}{ Lesion site } \\
\hline Left main & $13(9.4)$ & $3(6.8)$ & $10(10.6)$ & 0.550 \\
\hline Left artery descending artery & $59(42.7)$ & $19(43.1)$ & $40(42.5)$ & 1.000 \\
\hline Left circumflex artery & $49(35.5)$ & $16(36.3)$ & $33(35.1)$ & 1.000 \\
\hline Right coronary artery & 49 (35.5) & $14(31.8)$ & $35(37.2)$ & 0.572 \\
\hline Multi-vessel disease & $56(33.9)$ & $19(35.8)$ & $37(33.0)$ & 0.728 \\
\hline $1 \mathrm{VD}$ & $41(24.8)$ & $9(16.9)$ & $32(28.5)$ & \\
\hline 2VD & $34(20.6)$ & $13(24.5)$ & $21(18.7)$ & \\
\hline 3VD & $22(13.3)$ & $6(11.3)$ & $16(14.2)$ & \\
\hline CTO lesion & $23(13.9)$ & $6(11.3)$ & $17(15.1)$ & 0.633 \\
\hline Onsite elective PCI & $43(26.0)$ & $16(30.1)$ & $27(24.1)$ & 0.450 \\
\hline
\end{tabular}

Values are mean \pm SD (range). HTN indicates hypertension group, Pts patients, CAG coronary angiography, 1VD 1 vessel disease, 2VD 2 vessel disease, 3VD 3 vessel disease, CTO chronic total occlusion, $P C l$ percutaneous coronary intervention 
Table 3 Medications according to blood pressure control on admission and 30 days after BTK intervention

\begin{tabular}{|c|c|c|c|c|}
\hline Variable. n\% & $\begin{array}{l}\text { Total }(n=165 \text { Pts })(n=201 \text { Limb) } \\
(n=246 \text { Lesion })\end{array}$ & $\begin{array}{l}\text { Controlled HTN ( } n=53 \text { Pts }) \\
(n=66 \text { Limb) }(n=90 \text { Lesion) }\end{array}$ & $\begin{array}{l}\text { Uncontrolled HTN ( } n=112 \text { Pts) } \\
(n=135 \text { Limb) }(n=156 \text { Lesion) }\end{array}$ & $P$ Value \\
\hline \multicolumn{5}{|c|}{ In-hospital medications } \\
\hline Aspirin & $165(100.0)$ & $53(100.0)$ & $112(100.0)$ & 1.000 \\
\hline Clopidogrel & $152(92.1)$ & $48(90.5)$ & $104(92.8)$ & 0.758 \\
\hline Cilostazol & $81(49)$ & $28(52.8)$ & $53(47.3)$ & 0.617 \\
\hline Warfarin & $12(7.2)$ & $3(5.6)$ & $9(8.0)$ & 0.753 \\
\hline Sarpogrelate & $61(36.9)$ & 21 (39.6) & $40(35.7)$ & 0.730 \\
\hline Diuretics & $41(24.8)$ & $11(20.7)$ & $30(26.7)$ & 0.446 \\
\hline B-blockers & $58(35.1)$ & $21(39.6)$ & $37(33)$ & 0.485 \\
\hline Ca-blockers & $84(50.9)$ & $29(54.7)$ & $55(49.1)$ & 0.510 \\
\hline ACE-inhibitors & $36(21.8)$ & $10(18.8)$ & $26(23.2)$ & 0.687 \\
\hline ARBs & $73(44.2)$ & $25(47.1)$ & $48(42.8)$ & 0.618 \\
\hline Statins & $114(69)$ & $39(73.5)$ & $75(66.9)$ & 0.472 \\
\hline \multicolumn{5}{|c|}{30 days medications } \\
\hline Aspirin & 155 (93.9) & $52(98.1)$ & 103 (91.9) & 0.170 \\
\hline Clopidogrel & $140(84.8)$ & $48(90.5)$ & $92(82.1)$ & 0.244 \\
\hline Cilostazol & $54(32.7)$ & $20(37.7)$ & $34(30.3)$ & 0.377 \\
\hline Warfarin & $10(6.0)$ & $3(5.6)$ & $7(6.2)$ & 1.000 \\
\hline Sarpogrelate & $60(36.3)$ & 21 (39.6) & $39(34.8)$ & 0.605 \\
\hline
\end{tabular}

Values are mean \pm SD (range). BTK indicates Below-the-knee, HTN hypertension, Pts patients, ACE angiotensin converting enzyme, ARB angiotensin II receptor blocker

uncontrolled HTN group, which is consistent with the previous reports that severe HTN was more strongly associated with proximal disease [21], and the most important factor influencing the progression of atherosclerosis [22].

However, in this study, there was no difference in the incidence of mortality, TLR, TER, limb salvage rate in both groups at 12 months. Rather, amputation rate was higher in patients with controlled HTN compared to those with uncontrolled HTN $(P=0.045)$. Conversely, the patients with uncontrolled HTN had a trend of higher limb salvage rate than those with controlled HTN $(P=0.059)$. Therefore, it is difficult to interpret this result. Our speculation and interpretations includes 1) differences in amputation rates might be 'by chance' due to relatively small number of study population, 2) significant proportion of the controlled HTN pts might be associated with longer history of hypertension, causing higher chance of advanced atherosclerosis and subsequent end organ damage, 3) despite of successful BTK intervention, uncontrolled HTN group might have more advanced wound condition that cannot be adjusted at the time of presentation due to longer history of atherosclerotic vascular disease.

Among those with CLI enrolled in this study, there were common peripheral angiographic features regardless of BP control in both groups. More than half patients had above the knee lesions, more proximal lesion sites, total occlusion type of lesions in both groups and most of the patients ( $>90 \%)$ had diffuse long lesions $(\geq 2 \mathrm{~cm})$, which are consistent with the characteristics of unrecognized lower extremity peripheral artery disease in hypertensive adults [14]. And in this study, all patients with HTN $(n=165)$ had higher incidence of MALE compared to those without HTN $(n=15)$ at 12 month follow-up (37.6 \% vs. $6.7 \%, P$ $=0.021$ ). In this regard, we can postulate that HTN itself is an independent risk factor for BTK lesions in patients with CLI, regardless of BP control.

Increased pulse pressure (PP) is known to be associated with arterial stiffness, leading to increased arterial pulse wave velocity. This causes a faster reflection of systolic pulse waves from the peripheral artery and causes a boost to late systolic BP, a greater fall in pressure in diastole and an increased PP [23]. In hypertensive patients, arterial compliance was reduced already with borderline PAD and increasing arterial stiffness plays a major pathophysiological role in the development of both increased PP and atherosclerotic lesions in the peripheral arteries [24]. In this study, the patients with uncontrolled HTN had increased PP compared to those with controlled HTN (mean PP; $83.8 \pm 42.0$ vs. $57.7 \pm$ $0.8 \mathrm{mmHg}, P<0.001)$ as expected. However, there was no significant correlation between PP and 12-month clinical outcomes after BTK interventions in 
Table 4 Peripheral angiographic and clinical parameters of target lesions according to blood pressure control

\begin{tabular}{|c|c|c|c|c|}
\hline Variable. n\% & $\begin{array}{l}\text { Total }(n=165 \text { Pts })(n=201 \text { Limb) } \\
(n=246 \text { Lesion })\end{array}$ & $\begin{array}{l}\text { Controlled HTN ( } n=53 \text { Pts }) \\
(n=66 \text { Limb) }(n=90 \text { Lesion })\end{array}$ & $\begin{array}{l}\text { Uncontrolled HTN ( } n=112 \text { Pts }) \\
(n=135 \text { Limb) ( } n=156 \text { Lesion) }\end{array}$ & $P$ Value \\
\hline Ankle-brachial index & $0.65 \pm 0.4$ & $0.72 \pm 0.48$ & $0.62 \pm 0.4$ & 0.159 \\
\hline Rutherford classifications (Limb) & $5.01 \pm 1.48$ & $5.12 \pm 1.41$ & $4.95 \pm 1.52$ & 0.453 \\
\hline \multicolumn{5}{|l|}{ Limb site } \\
\hline Right & $108(65.4)$ & $35(66.0)$ & $73(65.1)$ & 1.000 \\
\hline Left & $93(56.3)$ & $31(58.4)$ & $62(55.3)$ & 0.739 \\
\hline Both & $36(21.8)$ & $13(24.5)$ & $23(20.5)$ & 0.552 \\
\hline \multicolumn{5}{|l|}{ Lesion locations } \\
\hline Above the knee - Pts & $82(49.6)$ & $25(47.1)$ & $57(50.8)$ & 0.739 \\
\hline Above the knee - Limb & $88(43.7)$ & $26(39.3)$ & $62(45.9)$ & 0.450 \\
\hline Iliac - Pts & $10(6.0)$ & $4(7.5)$ & $6(5.3)$ & 0.728 \\
\hline Iliac - Limb & $10(4.9)$ & $4(6.0)$ & $6(4.4)$ & 0.732 \\
\hline Femoral - Pts & 77 (46.6) & $24(45.2)$ & $53(47.3)$ & 0.868 \\
\hline Femoral - Limb & $83(41.2)$ & $25(37.8)$ & $58(42.9)$ & 0.543 \\
\hline Popliteal - Pts & $20(12.1)$ & $5(9.4)$ & $15(13.3)$ & 0.612 \\
\hline Popliteal - Limb & $21(10.4)$ & $6(9.0)$ & $15(11.1)$ & 0.808 \\
\hline \multicolumn{5}{|l|}{ Below the knee - Pts } \\
\hline \multicolumn{5}{|l|}{ Below the knee - Limb } \\
\hline Tibial - Pts & $156(94.5)$ & $49(92.4)$ & $107(95.5)$ & 0.470 \\
\hline Tibial - Limb & $183(91.0)$ & $57(86.3)$ & $126(93.3)$ & 0.119 \\
\hline ATA - Pts & $119(72.1)$ & $37(69.8)$ & $82(73.2)$ & 0.711 \\
\hline ATA - Limb & $140(69.6)$ & $43(65.1)$ & $97(71.8)$ & 0.333 \\
\hline PTA - Pts & $74(44.8)$ & $25(47.1)$ & $49(43.7)$ & 0.739 \\
\hline PTA - Limb & $76(37.8)$ & $26(39.3)$ & $50(37.0)$ & 0.759 \\
\hline Peroneal - Pts & $44(26.6)$ & $16(30.1)$ & $28(25.0)$ & 0.572 \\
\hline Peroneal - Limb & $47(23.3)$ & $17(25.7)$ & $30(22.2)$ & 0.598 \\
\hline \multicolumn{5}{|l|}{ Lesion site } \\
\hline Proximal & $151(61.3)$ & $45(50.0)$ & $106(67.9)$ & 0.007 \\
\hline Mid & $30(12.1)$ & 15 (16.6) & $15(9.6)$ & 0.110 \\
\hline Distal & $24(9.7)$ & $12(13.3)$ & $12(7.6)$ & 0.182 \\
\hline Ostium & $42(17)$ & $19(21.1)$ & $23(14.7)$ & 0.221 \\
\hline \multicolumn{5}{|l|}{ Lesion type } \\
\hline Concentric & $38(15.4)$ & $16(17.7)$ & $22(14.1)$ & 0.467 \\
\hline Eccentric & $61(24.7)$ & $20(22.2)$ & $41(26.2)$ & 0.541 \\
\hline Total occlusion & $147(59.7)$ & $54(60.0)$ & $93(59.6)$ & 1.000 \\
\hline \multicolumn{5}{|l|}{ Lesion characteristics } \\
\hline CTO & $119(48.3)$ & $35(38.8)$ & $84(53.8)$ & 0.025 \\
\hline Diffuse ( $\geq 2 \mathrm{~cm}$ ) & $231(93.9)$ & $83(92.2)$ & $148(94.8)$ & 0.418 \\
\hline Calcification & $119(48.3)$ & $36(40.0)$ & $83(53.2)$ & 0.048 \\
\hline \multicolumn{5}{|l|}{ Procedure } \\
\hline Sublntimal approach & $57(23.1)$ & $23(25.5)$ & $34(21.7)$ & 0.532 \\
\hline POBA & $228(92.6)$ & $84(93.3)$ & $144(92.3)$ & 1.000 \\
\hline Stent type & $18(7.3)$ & $6(6.6)$ & $12(7.6)$ & 1.000 \\
\hline Smart control & $1(0.4)$ & $1(1.1)$ & $0(0.0)$ & \\
\hline
\end{tabular}


Table 4 Peripheral angiographic and clinical parameters of target lesions according to blood pressure control (Continued)

\begin{tabular}{llll}
\hline Xpert & $14(5.6)$ & $3(3.3)$ & $11(7.0)$ \\
Chromis deep & $2(0.8)$ & $2(2.2)$ & $0(0.0)$ \\
Maris deep & $1(0.4)$ & $0(0.0)$ & $1(0.6)$ \\
Technical Success & $230(93.4)$ & $82(91.1)$ & $148(94.8)$ \\
Clinical Success & $232(94.3)$ & $85(94.4)$ & $147(94.2)$
\end{tabular}

Values are mean \pm SD (range). HTN indicates hypertension group, Pts patients, ATA anterior tibial artery, PTA posterior tibial artery, CTO chronic total occlusion, $P O B A$ plain old balloon angioplasty

hypertensive patients with CLI according to BP control $(P=0.497)$.

\section{Study limitation}

This study has several obvious limitations. First, we used retrospective analysis, although this study was performed as a prospective study. However, this study results is still meaningful due to the nature of study. We cannot perform randomized clinical trial with this exact title in terms of ethical issues.

Second, Uncontrolled HTN was defined as a blood pressure of $>140 \mathrm{mmHg}$ systolic and $90 \mathrm{mmHg}$ diastolic under anti-hypertensive treatment including patients who lack blood pressure control secondary to poor adherence and/or an inadequate treatment regimen, as well as those with true treatment resistance, which can be limitations due to the difference of pathophysiology between inadequate treatment and true treatment resistance. However, in this study, we showed that regardless of blood pressure control, HTN itself was an independent risk factor for MALE in CLI patients with BTK lesions. Third, there are small numbers of patients without HTN, which could be too small to compare with those with HTN. However, this study is retrospective observational study for the patients who underwent the peripheral angioplasties. Therefore, we could not enroll the patients without hypertension as a control group. Further a prospective study should be considered to get final conclusion.

Fourth, similar to many other trials in interventional cardiology, this was not a blinded study. In addition, patients were enrolled only in a single, high volume center that might have unique patient referral pattern and interventional technique. Fifth, even though we minimized the confounding effects from the baseline biases with multivariate logistic analysis, it is possible that some potential confounders might have crept in. Sixth, this study had no financial support, and no external angiography was available for adjudication of the end points. However, the size of the observed effect of uncontrolled HTN in the BTK lesions leaves few chances for these results to be controverted in a multicenter, randomized study. Finally, clinical results achieved by an integrated multidisciplinary approach to CLI in wellorganized specialized center may not be reproduced in patients with uncontrolled HTN in other centers with different organization.

\section{Conclusions}

Even though the patients with uncontrolled HTN had more proximal target lesions, higher incidences of CTO and severe calcifications, there was no difference in the

Table 5 Periprocedural complications according to blood pressure control

\begin{tabular}{|c|c|c|c|c|}
\hline Type of complications & $\begin{array}{l}\text { Total }(n=165 \text { Pts })(n=201 \text { Limb) } \\
(n=246 \text { Lesion) }\end{array}$ & $\begin{array}{l}\text { Controlled HTN ( } n=53 \text { Pts) } \\
(n=66 \text { Limb) ( } n=90 \text { Lesion) }\end{array}$ & $\begin{array}{l}\text { Uncontrolled HTN ( } n=112 \text { Pts) } \\
(n=135 \text { Limb) ( } n=156 \text { Lesion) }\end{array}$ & $P$ Value \\
\hline AV fistula & $1(0.6)$ & $1(1.8)$ & $0(0.0)$ & 0.321 \\
\hline Pseudo-aneurysm & $2(1.2)$ & $1(1.8)$ & $1(0.8)$ & 0.541 \\
\hline \multicolumn{5}{|l|}{ Access site hematoma } \\
\hline $\operatorname{minor}(<4 \mathrm{~cm})$ & $4(2.4)$ & $1(1.8)$ & $3(2.6)$ & 1.000 \\
\hline Major ( $\geq 4 \mathrm{~cm})$ & $14(8.4)$ & $4(7.5)$ & $10(8.9)$ & 1.000 \\
\hline G.I. bleeding & $4(2.4)$ & $0(0.0)$ & $4(3.5)$ & 0.307 \\
\hline Transfusion & $91(55.1)$ & $31(58.4)$ & $60(53.5)$ & 0.617 \\
\hline Transfusion (Unit) & $5.81 \pm 10.4$ & $6.9 \pm 11.2$ & $5.2 \pm 10.0$ & 0.325 \\
\hline Acute renal failure & $4(2.4)$ & $1(1.8)$ & $3(2.6)$ & 1.000 \\
\hline Congestive heart failure & $3(1.8)$ & $1(1.8)$ & $2(1.7)$ & 1.000 \\
\hline Arrhythmia & $4(2.4)$ & $2(3.7)$ & $2(1.7)$ & 0.594 \\
\hline
\end{tabular}

Values are mean \pm SD (range). HTN indicates hypertension group, Pts patients, AV arterio-venous, G.I. gastrointestinal 
Table 6 Clinical outcomes following BTK interventions in patients with CLI according to blood pressure control at 12 months

\begin{tabular}{|c|c|c|c|c|}
\hline Variable. $\mathrm{n} \%$ & $\begin{array}{l}\text { Total }(n=165 \text { Pts })(n=201 \text { Limb }) \\
(n=246 \text { Lesion })\end{array}$ & $\begin{array}{l}\text { Controlled HTN ( } n=53 \text { Pts }) \\
(n=66 \text { Limb) }(n=90 \text { Lesion })\end{array}$ & $\begin{array}{l}\text { Uncontrolled HTN ( } n=112 \text { Pts }) \\
(n=135 \text { Limb) }(n=156 \text { Lesion) }\end{array}$ & $P$ Value \\
\hline \multicolumn{5}{|l|}{ 12-months clinical outcomes } \\
\hline Mortality & $9(5.4)$ & $2(3.7)$ & $7(6.2)$ & 0.720 \\
\hline Cardiac death & $5(3.0)$ & $1(1.8)$ & $4(3.5)$ & 1.000 \\
\hline TLR, Pts & $18(10.9)$ & $6(11.3)$ & $12(10.7)$ & 0.907 \\
\hline TLR, Limb & $21(10.4)$ & $6(9)$ & $15(11.1)$ & 0.808 \\
\hline TER, Pts & $20(12.1)$ & $7(13.2)$ & $13(11.6)$ & 0.769 \\
\hline TER, Limb & $25(12.4)$ & $7(10.6)$ & $18(13.3)$ & 0.655 \\
\hline Non TER & $7(4.2)$ & $3(5.7)$ & $4(3.6)$ & 0.534 \\
\hline Amputations - Pts & $40(24.2)$ & $18(33.9)$ & $22(19.6)$ & 0.045 \\
\hline Amputations - Limb & $41(20.3)$ & $19(28.7)$ & $22(16.2)$ & 0.061 \\
\hline \multicolumn{5}{|l|}{ Major } \\
\hline above the knee & $0(0.0)$ & $0(0.0)$ & $0(0.0)$ & 1.000 \\
\hline above the ankle - Pts & $10(6.0)$ & $7(13.2)$ & $3(2.6)$ & 0.013 \\
\hline above the ankle - Limb & $10(4.9)$ & $7(10.6)$ & $3(2.2)$ & 0.016 \\
\hline minor (below the ankle) - Pts & $30(18.1)$ & $11(20.7)$ & 19 (16.9) & 0.556 \\
\hline minor (below the ankle) - Limb & $31(15.4)$ & $12(18.1)$ & $19(14)$ & 0.533 \\
\hline Myocardial infarction & $2(1.2)$ & $1(1.8)$ & $1(0.8)$ & 0.541 \\
\hline PTCA & $7(4.2)$ & $3(5.6)$ & $4(3.5)$ & 0.682 \\
\hline Cerebrovascular accidents & $1(0.6)$ & $0(0.0)$ & $1(0.8)$ & 1.000 \\
\hline Limb salvage & $147 / 156(94.2)$ & $45 / 51(88.2)$ & 102/105 (97.1) & 0.059 \\
\hline Angiogram to follow-up & $55(33.3)$ & $18(33.9)$ & $37(33)$ & 0.906 \\
\hline CT & $21(38.1)$ & $8(44.4)$ & $13(35.1)$ & 0.505 \\
\hline PAG & $42(76.3)$ & $13(72.2)$ & $29(78.3)$ & 0.738 \\
\hline Binary restenosis & 35 (63.6) & $11(61.1)$ & $24(64.8)$ & 0.786 \\
\hline Total re-occlusion & $29(52.7)$ & $8(44.4)$ & $21(56.7)$ & 0.391 \\
\hline Primary patency & $20(36.3)$ & $7(38.8)$ & $13(35.1)$ & 0.786 \\
\hline Secondary patency & $39(70.9)$ & $11(61.1)$ & $28(75.6)$ & 0.264 \\
\hline $\begin{array}{l}\text { Non-Total occlusion; Runoff }(\geq 1) \text { included } \\
\text { Collateral, to distal }\end{array}$ & $53(96.3)$ & $17(94.4)$ & $36(97.2)$ & 1.000 \\
\hline
\end{tabular}

Values are mean \pm SD (range). BTK indicates Below-the-knee artery, CLI critical limb ischemia, HTN hypertension, Pts patients, TLR target lesion revascularization, TER target extremity revascularization, PTCA percutaneous transluminal coronary angioplasty, CT computed tomography, PAG follow-up invasive peripheral angiography

Table 7 Univariate and multivariate Cox analyses for MALE in patients with CLI after peripheral angioplasty at 12-month follow-up

\begin{tabular}{|c|c|c|c|c|}
\hline & Univariate analysis & & Multivariate analysis & \\
\hline Variable. N (\%) & OR $(95 \%$ Cl) & $P$-Value & OR (95 \% C.I) & $P$-Value \\
\hline Hypertension (itself) & $2.093(1.106-4.098)$ & 0.017 & $3.867(1.625-9.199)$ & 0.002 \\
\hline DM foot & $1.903(0.935-3.876)$ & 0.076 & & \\
\hline RWMA & $2.342(1.190-4.608)$ & 0.014 & & \\
\hline Mitral valve calcification & $3.029(1.297-7.073)$ & 0.010 & $2.915(1.048-8.107)$ & 0.040 \\
\hline $\mathrm{CHF}$ & $2.342(1.190-4.608)$ & 0.014 & & \\
\hline CKD & $1.966(1.049-3.685)$ & 0.035 & & \\
\hline Dialysis & $3.000(1.496-6.014)$ & 0.002 & $5.221(1.184-23.02)$ & 0.029 \\
\hline
\end{tabular}

$O R$ odds ratio, $\mathrm{Cl}$ confidence interval, DM diabetes mellitus, RWMA reginonal wall motion abnormality, CHF congestive heart failure-systolic, CKD chronic kidney disease 


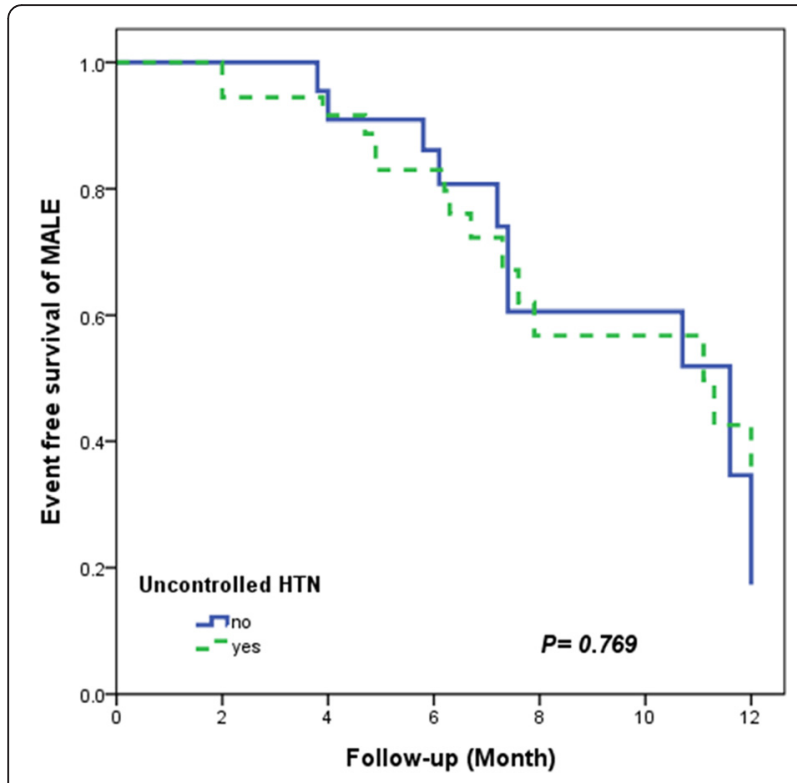

Fig. 2 Kaplan-Meier analysis for survival free from MALE in both study groups

incidence of major adverse events following BTK interventions in both groups at 12 months. Rather, the amputation rates were higher in patients with controlled HTN compared to those of uncontrolled HTN and there were common peripheral angiographic features regardless of BP control in both groups. Regardless of blood pressure control, HTN itself was an independent risk factor for MALE in CLI patients with BTK lesions, suggesting more intensive medical therapy with close clinical follow up will be required in real world clinical practice.

\section{Consent}

Written informed consent was obtained from the patient for the publication of this report and any accompanying images.

\section{Competing interests}

The authors declare that they have no competing interests.

\section{Authors' contributions}

SI Im and SW Rha were involved with research concept, data collection, data analysis, interpretation of results and writing of manuscript. BG Choi, SY Choi, SK Lee, JB Kim contributed to the research concept, interpretation of results and review of manuscript. JO Na, CU Choi, HE Lim, CG Park, HS Seo and DJ Oh were involved with the research concept, data analysis and drafting of manuscript. All authors reviewed and approved the final manuscript.

\section{Acknowledgements}

This study was supported by the funding of Korean Society of Hypertension (2012).

\section{Author details}

'Division of Cardiology, Department of Internal Medicine, Kosin University Gospel Hospital, Busan, South Korea. ${ }^{2}$ Cardiovascular Center, Korea University Guro Hospital, 80, Guro-dong, Guro-gu, Seoul 152-703, South Korea.
Received: 30 October 2015 Accepted: 21 January 2016

Published online: 29 February 2016

\section{References}

1. Yusuf S, Reddy S, Ounpuu S, Anand S. Global burden of cardiovascular diseases: Part II: variations in cardiovascular disease by specific ethnic groups and geographic regions and prevention strategies. Circulation. 2001;104:2855-64.

2. Kennedy M, Solomon C, Manolio TA, Criqui MH, Newman AB, Polak JF, et al. Risk factors for declining ankle-brachial index in men and women 65 years or older: the Cardiovascular Health Study. Arch Intern Med. 2005;165:1896-902.

3. Lee AJ, Price JF, Russell MJ, Smith FB, van Wijk MC, Fowkes FG. Improved prediction of fatal myocardial infarction using the ankle brachial index in addition to conventional risk factors: the Edinburgh Artery Study. Circulation. 2004;110:3075-80.

4. Yang $X$, Sun $K$, Zhang W, Wu H, Zhang H, Hui R. Prevalence of and risk factors for peripheral arterial disease in the patients with hypertension among Han Chinese. J Vasc Surg. 2007;46:296-302.

5. Farkas K, Jarai Z, Kolossvary E, Ludanyi A, Clement DL, Kiss I, et al. High prevalence of peripheral arterial disease in hypertensive patients: the Evaluation of Ankle-Brachial Index in Hungarian Hypertensives screening program. J Hypertens. 2012;30:1526-32

6. Newman AB. Peripheral arterial disease: insights from population studies of older adults. J Am Geriatr Soc. 2000;48:1157-62.

7. Wang TJ, Vasan RS. Epidemiology of uncontrolled hypertension in the United States. Circulation. 2005:112:1651-62.

8. Hajjar I, Kotchen TA. Trends in prevalence, awareness, treatment, and control of hypertension in the United States, 1988-2000. JAMA. 2003;290:199-206.

9. Taddei S, Virdis A, Mattei P, Ghiadoni L, Fasolo CB, Sudano I, et al. Hypertension causes premature aging of endothelial function in humans. Hypertension. 1997;29:736-43.

10. Taddei S, Virdis A, Ghiadoni L, Magagna A, Pasini AF, Garbin U, et al. Effect of calcium antagonist or beta blockade treatment on nitric oxidedependent vasodilation and oxidative stress in essential hypertensive patients. J Hypertens. 2001;19:1379-86.

11. Ferguson DW. Regular aerobic exercise augments endothelium-dependent vascular relaxation in normotensive and hypertensive subjects: role of endothelium-derived nitric oxide. Circulation. 2000;102:E119-20.

12. Cuddy ML. Treatment of hypertension: guidelines from JNC 7 (the seventh report of the Joint National Committee on Prevention, Detection, Evaluation, and Treatment of High Blood Pressure 1). J Pract Nurs. 2005;55:17-21. quiz 2-3.

13. Psaty $B M$, Lumley $T$, Furberg $C D$, Schellenbaum $G$, Pahor $M$, Alderman $M H_{\text {, }}$ et al. Health outcomes associated with various antihypertensive therapies used as first-line agents: a network meta-analysis. JAMA. 2003;289:2534-44.

14. He M, Qin X, Cui Y, Cai Y, Sun L, Xu X, et al. Prevalence of unrecognized lower extremity peripheral arterial disease and the associated factors in chinese hypertensive adults. Am J Cardiol. 2012;1 10:1692-8.

15. Zayed M, Bech F, Hernandez-Boussard T. National review of factors influencing disparities and types of major lower extremity amputations. Ann Vasc Surg. 2013.

16. Pua U, Wong DE. Angioplasty in critical limb ischaemia: one-year limb salvage results. Ann Acad Med Singapore. 2008;37:224-9.

17. Ryu HM, Kim JS, Ko YG, Hong MK, Jang Y, Choi D. Clinical outcomes of infrapopliteal angioplasty in patients with critical limb ischemia. Korean circulation journal. 2012;42:259-65.

18. Hooi JD, Kester AD, Stoffers HE, Overdijk MM, van Ree JW, Knottnerus JA. Incidence of and risk factors for asymptomatic peripheral arterial occlusive disease: a longitudinal study. Am J Epidemiol. 2001;153:666-72.

19. Resnick HE, Lindsay RS, McDermott MM, Devereux RB, Jones KL, Fabsitz RR, et al. Relationship of high and low ankle brachial index to all-cause and cardiovascular disease mortality: the Strong Heart Study. Circulation. 2004;109:733-9.

20. Tapp RJ, Balkau B, Shaw JE, Valensi P, Cailleau M, Eschwege E, et al. Association of glucose metabolism, smoking and cardiovascular risk factors with incident peripheral arterial disease: the DESIR study. Atherosclerosis. 2007;190:84-9.

21. Chen Q, Smith CY, Bailey KR, Wennberg PW, Kullo IJ. Disease location is associated with survival in patients with peripheral arterial disease. J Am Heart Assoc. 2013;2, e000304.

22. Nosenko NS, Nosenko EM, Dadova LV, Sidorenko BA. The risk factors and predictors of the clinically significant progression of atherosclerosis in patients with chronic lower extremity ischemia. Ter Arkh. 2010;82:56-60.

23. van Popele NM, Bos WJ, de Beer NA, van Der Kuip DA, Hofman A, Grobbee DE, et al. Arterial stiffness as underlying mechanism of disagreement between an 
oscillometric blood pressure monitor and a sphygmomanometer. Hypertension. 2000;36:484-8.

24. Korhonen PE, Syvanen KT, Vesalainen RK, Kantola IM, Kautiainen $H$, Jarvenpaa $\mathrm{S}$, et al. Ankle-brachial index is lower in hypertensive than in normotensive individuals in a cardiovascular risk population. J Hypertens. 2009:27:2036-43

Submit your next manuscript to BioMed Central and we will help you at every step:

- We accept pre-submission inquiries

- Our selector tool helps you to find the most relevant journal

- We provide round the clock customer support

- Convenient online submission

- Thorough peer review

- Inclusion in PubMed and all major indexing services

- Maximum visibility for your research

Submit your manuscript at www.biomedcentral.com/submit 